\title{
Income-Related Inequity in Initiation of Evidence-Based Therapies Among Patients with Acute Myocardial Infarction
}

\author{
Gillian E. Hanley, $P h D^{7}$, Steve Morgan, $P h D^{7}$, and Robert J. Reid, MD, $P h D^{2}$ \\ 'Centre for Health Services and Policy Research, School of Population and Public Health, University of British Columbia, Vancouver, BC, \\ Canada; ${ }^{2}$ Group Health Research Institute, Seattle, WA, USA.
}

BACKGROUND: Previous research has shown a socioeconomic status (SES) gradient in the receipt of cardiac services following acute myocardial infarction (AMI), but much less is known about SES and the use of secondary preventive medicines following AMI.

OBJECTIVES: To examine the role of income in initiation of treatment with ACE-inhibitors, beta-blockers and statins in the 120 days following discharge from hospital for first AMI.

DESIGN: A cross-sectional study with a populationbased cohort.

PARTICIPANTS: First-time AMI patients between age 40 and 100 discharged alive from the hospital and surviving at least 120 days following discharge between January 1, 1999 and September 3, 2006.

MAIN MEASURES: Binary variables indicating whether the patient had filled at least one prescription for each of the medicines of interest.

KEY RESULTS: Our results reveal a significant and positive income gradient with initiation of the guideline-recommended medicines among male AMI patients. Men in the third income quintile and above were significantly more likely to initiate treatment with any of the medicines than those in the first quintile, with those in the fifth income quintile having $37 \%, 50 \%$ and $71 \%$ higher odds of initiating ACEinhibitors, beta-blockers and statins, respectively, than men in the lowest income quintile [OR $=1.37$ $95 \%$ CI $(1.24,1.51)$; OR $=1.5095 \%$ CI $(1.35,1.68)$; and $\mathrm{OR}=1.7195 \%$ CI $(1.53,190)]$. The gradient was not present among women, although women in the fifth income quintile were more likely to initiate betablockers and statins than women in the lowest income quintile [OR $=1.2595 \% \mathrm{CI}(1.06,1.47)$ and $\mathrm{OR}=1.32$ 95\% CI $(1.12,1.54)]$.

CONCLUSIONS: There were inequities in treatment following AMI in the form of a clear and often significant gradient between income and initiation of evidence-based pharmacologic therapies among male patients. This gradient persisted despite significant changes in coverage levels for the costs of these medicines.

Electronic supplementary material The online version of this article (doi:10.1007/s11606-011-1799-1) contains supplementary material, which is available to authorized users.

Received April 7, 2011

Revised June 13, 2011

Accepted June 20, 2011

Published online July 13, 2011
KEY WORDS: access to care; cardiovascular disease; pharmaceutical care; socioeconomic factors.

J Gen Intern Med 26(11):1329-35

DOI: $10.1007 / \mathrm{s} 11606-011-1799-1$

(C) The Author(s) 2011. This article is published with open access at Springerlink.com

\section{INTRODUCTION}

Despite Canada's universal health insurance, research has shown that socioeconomic status (SES) affects receipt of cardiac procedures following an acute myocardial infarction (AMI): previous studies have reported that AMI patients with higher SES are more likely to receive cardiac catheterization ${ }^{1,2}$ and coronary angiography ${ }^{3}$ than are more disadvantaged patients. Some research has suggested that prescribing for secondary prevention may be influenced by non-clinical factors such as patient age and education ${ }^{4}$. However, the potential relationship between SES and receipt of recommended prescription medicines following AMI remains unclear.

Pharmacologic therapy is safe and effective in the secondary prevention of coronary artery disease. Generally accepted clinical practice guidelines recommend that all patients without contraindications or intolerance be treated with acetylsalicylic acid (ASA), beta-blockers, angiotensin-converting enzyme (ACE) inhibitors and cholesterol-lowering statins ${ }^{5-7}$ to prevent secondary events. Guidelines recommend the combined use of all four medicines as each of these agents has been shown to reduce the risk of death and reinfarction ${ }^{8-10}$, and combination use provides the largest reduction in risk $^{11}$. Despite these guidelines, we know that not all eligible AMI patients receive these pharmacotherapies ${ }^{12,13}$.

Given that all first-time AMI patients have the same level of need for these therapies, if the health care system was achieving its stated goals of promoting the use of effective medicines according to need rather than ability-to-pay, we would expect no significant differences in the initiation of recommended treatment following AMI across income groups (as a measure of SES) 14,15 . To test this (null) hypothesis, we performed a populationbased province-wide study of the initiation of treatment with ACE-inhibitors, beta-blockers and statins in the 120 days following discharge from the hospital for first AMI in British Columbia (BC).

We also sought to determine whether the relationship between income and initiation of these medicines persisted after the drug benefits structure changed in BC. While pharmaceuticals used in outpatient settings are not included 
in the Canadian universal health insurance plan, prior to May 2003 BC provided relatively comprehensive public drug coverage for seniors (age $\geq 65$ ), where seniors were responsible for small co-pays on medicines up to an annual maximum of \$200 for low-income seniors and \$275 for other seniors, and a catastrophic coverage program for non-seniors (offering $70 \%$ coverage after $\$ 1,000$ and $100 \%$ coverage after $\$ 4,333$ ). In May 2003, BC moved to a pharmacare program with income-based coinsurance and deductibles regardless of age, which increased the cost of medicines for many seniors in the province ${ }^{16,17}$. This policy change may have altered associations between income and access to medicines.

\section{METHODS}

We performed a cross-sectional study with a population-based cohort. Our data sets include all residents of BC except those whose health care is under federal jurisdiction: registered first nations, veterans, RCMP and inmates of federal penitentiaries (approximately $4 \%$ of the total population) ${ }^{18}$. We were provided data from Population Data BC and the BC PharmaNet with the permission of the BC Ministry of Health Services and the BC College of Pharmacists. Ethics approval was obtained from the Behavioural Research Ethics Board at the University of British Columbia.

\section{STUDY POPULATION}

Figure 1 outlines the exclusion criteria for our study population. Using automated hospital discharge records, we identified all patients who were admitted between January 1, 1999 and September 3, 2006 to any acute care hospital in BC with a primary diagnosis of AMI (ICD version 10 I21.x and ICD version 9 410.x). We restricted our analysis to patients aged 40 to 100 years who were discharged alive between January 1 , 1999 and September 3, 2006, and who had no previous diagnosis of AMI during the 5 years prior. We identified previous AMI by searching the hospital data for the 5 years prior to the identified AMI to determine whether the patient had been previously admitted to any acute care hospital in BC with a primary diagnosis of AMI (same codes as above). The first AMI event was considered the index AMI. We used the ICD-10 diagnoses in the hospital discharge data for the index AMI admission to eliminate patients with comorbidities that could be considered contraindications to treatment with one or more of the three medicines of interest. These included cirrhosis, cholestatisis, chronic obstructive pulmonary disorder, asthma, bradycardia, end-stage renal disease and aortic stenosis $^{19}$.

In order to ensure we had accurate health care and prescription data for our study population, we also eliminated individuals who were not registered for the provincial health care program for at least 275 days in each of the 4 years prior and the 1 year after their index AMI. Finally, we also eliminated individuals who did not survive for 120 days and those who were in long-term care settings in the year following their index AMI.

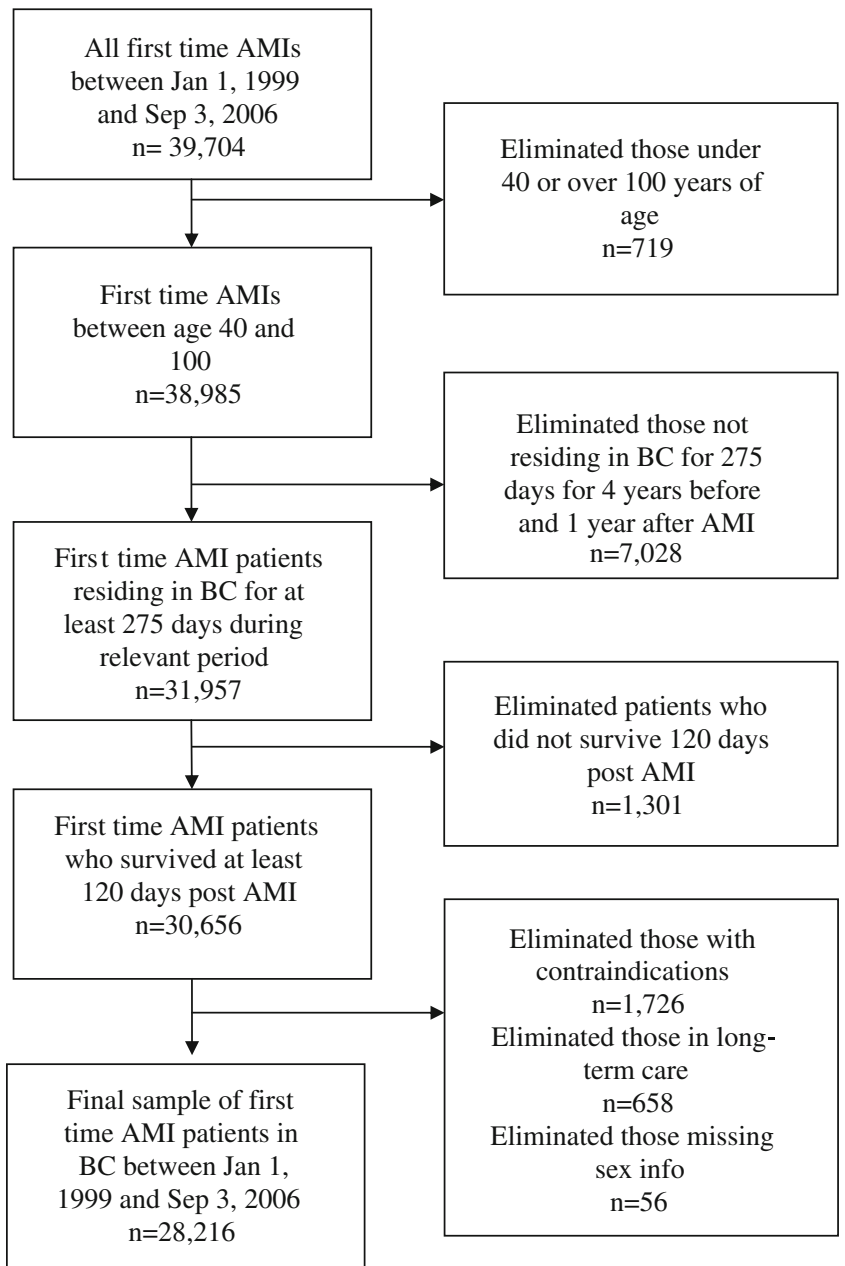

Figure 1. Sample description information.

\section{DATA AND VARIABLE CONSTRUCTION}

Prescription Drug Information. Prescription drug data were obtained from the BC PharmaNet, which contains records of all prescriptions filled at community pharmacies and longterm care facilities in BC. Regardless of payer, pharmacists enter medication names, dose and dispensed quantity for all dispensed prescriptions into this database via a provincewide network that ensures minimal reporting error and misclassification ${ }^{20}$. We used Anatomical Therapeutic Classification (ATC) codes to identify medicines of interest: ACE-inhibitors (ATC: C09), Beta Blockers (ATC: C07) and Statins (ATC: $\mathrm{C} 10 \mathrm{~A}$ and $\mathrm{C} 10 \mathrm{~B})^{21}$. We built a variable indicating whether or not a patient initiated if they filled at least one prescription for the medicines listed above within the 120 days after discharge from hospital for their index AMI. We did not include acetylsalicylic acid because it is also available over-the-counter in British Columbia and thus would not be completely captured in the BC PharmaNet.

Health Status and Residence Information. Popdata BC maintains linkable data on all physician services and 
hospitalizations for all persons in BC. The hospital discharge data include up to 25 diagnoses, while 1 diagnosis for each medical service is included. These data sets have been shown to have good specificity and completeness $^{22}$. We constructed measures of general health status using the diagnosis-based Adjusted Clinical Group (ACG) Case-Mix System ${ }^{23}$. Specifically, we used the Aggregated Diagnostic Groups, which were built from the complement of ICD-9/ICD-10 diagnostic codes assigned in inpatient and ambulatory settings over the 12-month period prior to their index AMI. The ADGs have been shown to be predictive of both prescription drug use and expenditure in the $\mathrm{BC}$ population ${ }^{24}$. A larger number of ADGs indicates a higher comorbidity burden and worse health status. Our indicator of urban residence was built using the Local Health Area in which the patient resided at the time of their index AMI. Local Health Areas that are located in urban centres were used to build an indicator variable of urban residence.

Income Information. Our income measure consisted of binary variables indicating quintile groups ordered from lowest to highest household incomes. For approximately $80 \%$ of the population, the underlying income data were derived from household-level incomes verified with the Canada Revenue Agency by the BC Ministry of Health Services. For the remaining AMI patients, we used a validated area-level measure of the mean income of the neighborhood in which they live, with neighborhoods including approximately 400700 residents $^{25}$.

\section{STATISTICAL ANALYSIS}

We compared average initiation rates across income quintiles using F-tests to assess whether the mean rate of initiation differed across income groups for both women and men separately. We also ran sex-stratified multivariate logistic regressions with four dependent variables indicating initiation of treatment in the 120 days post-discharge on ACE-inhibitors, beta-blockers, statins and all three of those medicines. We controlled for age using 5-year bands, general health status using the ADGs and an indicator of urban residence. We also calculated sex-stratified crude rates of initiation on each of those dependent variables. To examine whether the relationships between income and treatment changed after income-based coverage was introduced, we reran the models with the addition of a policy change indicator variable and interaction terms for each income quintile and the policy change. If the relationship between the income quintiles and initiation of treatment was significantly different after the policy change, the coefficients on those interaction terms would be significant. We also performed several sensitivity analyses to test the effects of using neighborhood-level income as well as individual-level income and found that our results were robust. We also performed sensitivity analyses examining the relationship between income and initiation only among the sample of working age AMI patients to examine potential confounding between age and income. Again, we found that our results were robust.

\section{RESULTS}

A total of 28,216 AMI patients met our eligibility criteria. Patients were more likely to be male across all income quintiles; however, this difference was more pronounced in higher income quintiles (Table 1). This likely reflects the fact that female AMI patients are older and thus less likely to be earning employment income than their male counterparts. Patients in the highest income quintile were slightly younger than patients in other income quintiles. Those in the highest income quintile were also slightly more likely to live in urban areas and were generally in better health (as measured by their fewer number of ADGs) than those in lower income quintiles. It should be noted that for all sex-stratified analyses, sexstratified income quintiles were used, so there were equal numbers of women in each income quintile, and our results were not affected by the sex differences across income quintiles reported in Table 1.

Crude rates of initiation of ACE-inhibitors, beta-blockers, statins and all three medicines as well as 95\% confidence intervals are listed in Table 2. Table 2 also notes the mean income in each quintile for both men and women. Men had higher mean incomes in each quintile than women. For male AMI patients, those in income quintiles 4 and 5 had significantly higher rates of initiation for all medicines following AMI than those in quintiles 1,2 and 3. While the same was true for women with respect to initiating treatment with beta-blockers, there were generally fewer significant differences in initiation rates across the income gradient for women. However, Fstatistics reject the null hypothesis that the mean rate of initiation is the same across income quintiles for both men and women and for all of the medicines studied (Table 2).

Tables 3 and 4 present adjusted odds ratios modeling the relationship between income quintile and likelihood of initia-

Table 1. Distribution of Variables in the AMI Study Population

\begin{tabular}{|c|c|c|c|c|c|}
\hline \multirow[b]{2}{*}{$\begin{array}{l}\text { Variable } \\
(\%)\end{array}$} & \multicolumn{4}{|c|}{ Income quintiles } & \multirow[b]{2}{*}{$\begin{array}{l}5 \\
(n=5,643)\end{array}$} \\
\hline & $\begin{array}{l}1 \\
(n=5,644)\end{array}$ & $\begin{array}{l}2 \\
(n=5,643)\end{array}$ & $\begin{array}{l}3 \\
(n=5,643)\end{array}$ & $\begin{array}{l}4 \\
(n=5,643)\end{array}$ & \\
\hline \multicolumn{6}{|l|}{ Sex } \\
\hline Male & 55.0 & 61.8 & 66.1 & 73.5 & 79.8 \\
\hline Female & 45.0 & 38.2 & 34.0 & 26.5 & 20.2 \\
\hline \multicolumn{6}{|l|}{ Age, years } \\
\hline 40 to 49 & 8.7 & 6.5 & 7.8 & 8.4 & 13.4 \\
\hline 50 to 59 & 18.5 & 13.2 & 15.3 & 20.0 & 32.2 \\
\hline 60 to 69 & 23.9 & 22.2 & 23.5 & 26.8 & 24.2 \\
\hline 70 to 79 & 23.4 & 31.0 & 31.3 & 28.6 & 19.3 \\
\hline 80 to 89 & 20.4 & 23.6 & 19.4 & 14.8 & 9.9 \\
\hline 90 to 99 & 5.1 & 3.6 & 2.7 & 1.5 & 0.9 \\
\hline \multicolumn{6}{|l|}{ Residence } \\
\hline Urban & 74.5 & 70.1 & 69.5 & 75.9 & 78.3 \\
\hline Rural & 25.5 & 29.9 & 30.5 & 24.1 & 21.7 \\
\hline \multicolumn{6}{|c|}{ General health status } \\
\hline Mean ADGs & 7.5 & 7.3 & 7.1 & 7.0 & 6.7 \\
\hline
\end{tabular}


Table 2. Crude Rates of Initiation of ACE-Inhibitors, Beta-Blockers, Statins and All Three Medicines in the 120 Days Post-Discharge from Hospital for AMI

\begin{tabular}{|c|c|c|c|c|}
\hline Income quintile (Mean income in quintiles) & ACE-inhibitors $(95 \% \mathrm{Cl})$ & Beta-blockers $(95 \% \mathrm{Cl})$ & Statins $(95 \% \mathrm{Cl})$ & All three $(95 \% \mathrm{Cl})$ \\
\hline Men & $\mathrm{n}=3,795$ & $\mathrm{n}=3,794$ & $\mathrm{n}=3,794$ & $\mathrm{n}=3,794$ \\
\hline Quintile $1(\$ 14,800)$ & $61.8(60.3,63.4)$ & $68.1(66.7,70.0)$ & $64.4(62.9,65.9)$ & $42.8(41.2,44.3)$ \\
\hline Quintile $2(\$ 28,500)$ & $61.3(59.7,62.8)$ & $67.6(66.1,69.0)$ & $62.0(60.4,63.5)$ & $39.4(37.9,41.0)$ \\
\hline Quintile $3(\$ 38,450)$ & $64.2(62.6,65.7)$ & $72.0(70.6,73.4)$ & $68.2(66.7,69.6)$ & $43.3(41.7,44.9)$ \\
\hline Quintile $4(\$ 54,600)$ & $68.9(67.4,70.3)$ & $75.7(74.3,77.0)$ & $74.9(73.6,76.3)$ & $48.8(47.2,50.4)$ \\
\hline Quintile $5(\$ 105,000)$ & $71.0(70.4,73.0)$ & $78.8(77.5,80.1)$ & $78.8(77.4,80.2)$ & $52.4(50.8,54.0)$ \\
\hline F-statistic & 109.5 (p-value <0.0000) & 163.4 (p-value <0.0000) & 309.1 (p-value <0.0000) & 120.0 (p-value <0.0000) \\
\hline Women & $\mathrm{n}=1,849$ & $\mathrm{n}=1,849$ & $\mathrm{n}=1,849$ & $\mathrm{n}=1,849$ \\
\hline Quintile $1(\$ 11,400)$ & $59.3(57.0,61.5)$ & $66.1(63.9,68.2)$ & $57.1(54.8,59.3)$ & $33.5(31.3,35.6)$ \\
\hline Quintile $2(\$ 22,900)$ & $61.3(59.0,63.5)$ & $67.2(65.1,69.4)$ & $57.2(55.0,59.5)$ & $33.4(31.3,35.6)$ \\
\hline Quintile $3(\$ 30,500)$ & $59.1(56.9,61.4)$ & $69.1(67.0,(71.1)$ & $57.8(55.5,60.0)$ & $34.1(32.0,36.3)$ \\
\hline Quintile $4(\$ 40,400)$ & $63.7(61.5,65.9)$ & $70.0(67.9,72.1)$ & $62.0(59.8,64.2)$ & $35.9(33.7,38.1)$ \\
\hline Quintile $5(\$ 82,150)$ & $64.3(62.1,66.5)$ & $74.0(72.0,76.0)$ & $69.9(67.8,72.0)$ & $42.9(40.6,45.1)$ \\
\hline F-statistic & $6.5(\mathrm{p}$-value $=0.0110)$ & 27.1 (p-value < 0.0000) & 72.3 (p-value < 0.0000) & 28.5 (p-value < 0.0000) \\
\hline
\end{tabular}

tion of treatment with ACE-inhibitors, beta-blockers, statins and all three medicines in the 120 days post-discharge from hospital after first AMI in men and women, respectively. After age, general health status and urban residence were accounted for, men in the third income quintile or higher were significantly more likely to initiate ACE-inhibitors, beta-blockers and statins than men in the first income quintile. Men in the fifth income quintile had $37 \%, 50 \%$ and $71 \%$ higher odds of initiating ACE-inhibitors, beta-blockers and statins, respectively, than those in the lowest income quintile [OR $=1.3795 \%$ CI $(1.24,1.51) ; \mathrm{OR}=1.5095 \%$ CI $(1.35,1.68)$; and $\mathrm{OR}=1.71$ 95\% CI $(1.53,190)]$. Adhering with treatment guidelines and initiating all three medicines was significantly more likely for men in the 4th and 5th income quintiles [OR $=1.1295 \% \mathrm{CI}$ $(1.02,1.24)$ and $\mathrm{OR}=1.3095 \% \mathrm{CI}(1.18,1.43)]$.

Table 4 suggests that the adjusted relationship between household income and initiation of treatment is not as clear among women. Women in the fourth income quintile were more likely to initiate ACE-inhibitors than those in the lowest income quintile [OR $=1.1595 \%$ CI $(1.01,1.32)]$. Women in the highest income quintile were also significantly more likely to use betablockers and statins than those in the lowest income quintile [OR $=1.2595 \%$ CI $(1.06,1.47)$ and OR $=1.3295 \%$ CI $(1.12,1.54)]$. There were no significant differences in initiation of treatment with all three medicines; however, the mean rate of initiation on all three medicines among women is a relatively low $36.0 \%$.

As an example of the results found when examining the use of medicines before and after the policy change, Table 5 contains results of sex-stratified models describing use of ACE-inhibitors and includes the policy change indicator and interaction terms. None of the interaction terms between the income quintiles and the policy change are significant in either of the sex-stratified models, suggesting that the relationship between income and initiation of treatment was not significantly affected by the policy change. These interactions between income and the policy change were insignificant in models for all dependent variables studied (results available in an online appendix). Models run separately pre-policy and post-policy also demonstrated that income gradients existed before and after the policy change (results also available in an online appendix).

\section{DISCUSSION}

In this population-based province-wide study, we demonstrated a clear and significant gradient between income and initiation of evidence-based pharmacologic therapies postAMI among male patients. Given that we removed patients with a contraindication for any of the recommended therapies we studied, and that all of these patients were in equal need for these effective treatments, we did not expect to see a significant effect of income on use of these medicines. The significant gradient between income and initiation of treatment did not appear among female patients, although women in the highest income quintiles were more likely to use statins and betablockers than those in the lowest quintile. This may be partly explained by the fact that the differences in mean income across income quintiles were greater for male AMI patients than for female AMI patients.

We also found that the relationship between income and initiation of medicines did not significantly change despite a policy change that substantially altered the way subsidies

Table 3. Men: Regression Results for Initiation of ACE-Inhibitors, Beta-Blockers and Statins in the 120 Days Post-AMI by Income Quintile

\begin{tabular}{|c|c|c|c|c|}
\hline & ACE-inhibitors & Beta-blockers & Statins & All three \\
\hline Quintile 1 & 1.00 (ref) & 1.00 (ref) & 1.00 (ref) & 1.00 (ref) \\
\hline Quintile 2 & $0.99(0.89,1.09)$ & $1.04(0.93,1.15)$ & $0.96(0.87,1.07)$ & $0.93(0.84,1.03)$ \\
\hline Quintile 3 & $1.13(1.02,1.25)$ & $1.21(1.09,1.35)$ & $1.15(1.03,1.28)$ & $1.03(0.93,1.14)$ \\
\hline Quintile 4 & $1.21(1.09,1.33)$ & $1.35(1.21,1.51)$ & $1.45(1.30,1.62)$ & $1.12(1.02,1.24)$ \\
\hline Quintile 5 & $1.37(1.24,1.51)$ & $1.50(1.35,1.68)$ & $1.71(1.53,1.90)$ & $1.30(1.18,1.43)$ \\
\hline
\end{tabular}

Note: Adjusted for age using 5-year age bands, urban residence and general health status using Johns Hopkins ADGs 
Table 4. Women: Regression Results for Initiation of ACE-Inhibitors, Beta-Blockers and Statins in the 120 Days Post-AMI by Income Quintile

\begin{tabular}{lllr}
\hline & ACE-inhibitors & Beta-blockers & Statins \\
\hline Guintile 1 & $1.00($ ref) & 1.00 (ref) & $1.00($ ref) \\
Guintile 2 & $1.01(0.87,1.11)$ & $1.00(0.88,1.14)$ & $0.94(0.83,1.06)$ \\
Quintile 3 & $0.98(0.89,1.13)$ & $1.05(0.92,1.20)$ & $0.98(0.86,1.11)$ \\
Quintile 4 & $1.15(1.01,1.32)$ & $1.13(0.97,1.30)$ & $1.07(0.93,1.23)$ \\
Quintile 5 & $1.04(0.89,1.20)$ & $1.25(1.06,1.47)$ & $0.91(0.80,1.04)$ \\
\hline
\end{tabular}

Note: Adjusted for age using 5-year age bands, urban residence and general health status using Johns Hopkins ADGs

were allocated in $\mathrm{BC}$ during our study period. Given that many of these patients faced very small copayments prior to the policy change (maximum annual private payment of $\$ 200$ or \$275 annually), our finding might suggest that costsharing may not be the only income-related barrier to receiving these evidence-based medicines. Because we did not have access to education data, we were unable to determine whether there was confounding between education and income that might explain the gradient we have seen. For example, it is possible that low-income AMI patients were less likely than high-income AMI patients to be fully aware of the importance of adhering to their secondary preventive therapies. However, our results might also indicate that even very small copayments represent a large enough barrier to discourage initiation and use among those of lower incomes. Previous research illustrating that even very small copayments often represent access barriers among vulnerable populations supports this hypothesis ${ }^{26-33}$

Our results are consistent with a study from Denmark that found that despite a generous health insurance system, AMI patients with low income received secondary preventive treatment with pharmacotherapies less frequently than their higher income counterparts ${ }^{34}$. Research in Sweden has also suggested that adherence to these therapies following AMI is higher among higher income patients ${ }^{35}$, and American research has previously reported increased sensitivity to copayments among patients living in lower income neigh-

Table 5. Regression Results Examining Whether the Relationship Between Income and Initiation of ACE-Inhibitors Changed After the Policy Change

\begin{tabular}{lll}
\hline \hline Variable & Men & Women \\
\hline Quintile 1 & $1.00(\mathrm{ref})$ & $1.00(\mathrm{ref})$ \\
Quintile 2 & $1.03(0.89,1.18)$ & $0.98(0.83,1.17)$ \\
Quintile 3 & $1.18(1.03,1.36)$ & $0.96(0.81,1.14)$ \\
Quintile 4 & $1.24(1.08,1.42)$ & $1.10(0.91,1.33)$ \\
Quintile 5 & $1.29(1.12,1.48)$ & $1.03(0.84,1.27)$ \\
Post-policy indicator & $1.16(0.99,1.34)$ & $0.82(0.70,0.97)$ \\
variable & & \\
Quintile 1 pre-policy & $1.00(\mathrm{ref})$ & $1.00(\mathrm{ref})$ \\
$\begin{array}{l}\text { Quintile 2 interacted } \\
\text { with post-policy variable }\end{array}$ & $0.95(0.78,1.17)$ & $0.97(0.76,1.24)$ \\
$\begin{array}{l}\text { Quintile 3 interacted } \\
\text { with post-policy variable }\end{array}$ & $0.93(0.76,1.14)$ & $0.97(0.75,1.24)$ \\
Quintile 4 interacted \\
$\begin{array}{l}\text { with post-policy variable } \\
\text { Quintile 5 interacted }\end{array}$ & $0.97(0.79,1.18)$ & $1.06(0.81,1.38)$ \\
with post-policy variable & $1.18(0.97,1.45)$ & $0.97(0.72,1.30)$ \\
\hline
\end{tabular}

Note: Adjusted for age using 5-year age bands, urban residence and general health status using Johns Hopkins ADGs bourhoods $^{36}$. We also know that Medicare patients with more generous coverage consume more clinically essential medicines ${ }^{37,38}$, that increased cost-sharing is associated with lower rates of drug treatment ${ }^{26}$ and that approximately $20 \%$ of cardiovascular patients cut back on their medicines because of $\operatorname{cost}^{39}$. The consequences of cost-related nonadherence or lack of initiation of recommended medical treatment are particularly serious in AMI populations. Cardiovascular patients not taking their medicines because of cost have been shown to be at increased risk for both hospitalization and death ${ }^{32,39,40}$.

Our study is not without limitations. Our inability to control for education means there could be some unobserved confounding by education that is not acknowledged; however, even if our results can be explained by differences in education across income quintiles, they would still indicate an important socioeconomic status gradient in care. Given our use of administrative data, it is unlikely that our attempt to exclude patients with contraindications to the therapies under consideration captured all such patients. We were also unable to identify patients who may have experienced intolerance to one or more of these medicines when using them for primary prevention. However, we would not expect missed contraindications or intolerance to exhibit an income gradient, and thus these limitations are unlikely to seriously affect our main findings. We were also unable to examine the use of ASA because the administrative data set only captures prescription medicines, and many patients may have been using ASA purchased over the counter. However, the use of administrative data allowed us to examine the entire population of patients suffering their first AMI in the province between 1999 and 2006. Therefore, our data are comprehensive, and not restricted to certain care facilities or to certain age groups or sub-populations.

Another limitation is that our data only captured filled prescriptions; we could not capture written but unfilled prescriptions. We were also unable to control for the specialty of the physician. Previous research has found that rates of post-discharge use of statins and ACE-inhibitors are higher in patients attended by cardiologists than noncardiologists ${ }^{12}$. Further research should examine whether the income gradient in initiation of treatment with recommended medicines differs for those attended by cardiologists.

Our results suggest that there was a clear and positive income gradient in filled prescriptions for the recommended medicines shown to be safe and effective for secondary prevention among male AMI patients. Physicians and pharmacists should be aware that their lower income male AMI patients may be at higher risk of not filling their prescriptions, and advise and prescribe accordingly. Physicians may 
want to prescribe generic and less expensive medicines, while pharmacists may want to pay special attention to counseling patients about the benefits of these medicines. Insurers should also consider the potential benefits of providing these medicines free of cost to AMI patients. A recent economic evaluation conducted to explore the potential effects of full public coverage of medicines for secondary prevention reported that full coverage was cost-effective in the Canadian system compared to the status quo, and resulted in greater adjusted survival of AMI patients ${ }^{41}$. Given that our research suggests the potential to alleviate important income-related inequities, and to significantly improve the number of AMI patients receiving these recommended treatments, it may be time for governments or insurers to seriously consider full coverage for secondary prevention for AMI patients.

Acknowledgments: $G E H$ is is supported by the Canadian Institutes of Health Research, the Michael Smith Foundation for Health Research and the Western Regional Training Centre. SM is supported by the Canadian Institutes of Health Research and the Michael Smith Foundation for Health Research. RJR is supported by Group Health cooperative. Sponsors had no role in this study or the decision to publish the results.

\section{Conflict of Interest: None disclosed}

Open Access: This article is distributed under the terms of the Creative Commons Attribution Noncommercial License which permits any noncommercial use, distribution, and reproduction in any medium, provided the original author(s) and source are credited.

Corresponding Author: Gillian E. Hanley, PhD; (email: ghanley@chspr.ubc.ca).

\section{REFERENCES}

1. Alter DA, Naylor CD, Austin P, Tu JV. Effects of socioeconomic status on access to invasive cardiac procedures and on mortality after acute myocardial infarction. N Engl J Med. 1999;341(18):1359-67.

2. Pilote L, Joseph L, Bélisle P, Penrod J. Universal health insurance coverage does not eliminate inequities in access to cardiac procedures after acute myocardial infarction. Am Heart J. 2003;146(6):1030-7.

3. Alter DA, Naylor CD, Austin PC, Chan BT, Tu JV. Geography and service supply do not explain socioeconomic gradients in angiography use after acute myocardial infarction. CMAJ. 2003;168(3):261-4.

4. Gnavi R, Migliardi A, Demaria M, Petrelli A, Caprioglio A, Costa G. Statins prescribing for the secondary prevention of ischaemic heart disease in torino, italy. A case of ageism and social inequalities. Eur $\mathrm{J}$ Pub Health. 2007;17(5):492-6.

5. Antman EM, Hand M, Armstrong PW, et al. 2007 focused update of the ACC/AHA 2004 guidelines for the management of patients with STelevation myocardial infarction: A report of the American College of Cardiology/American Heart Association task force on practice guidelines: Developed in collaboration with the Canadian Cardiovascular Society endorsed by the American Academy of Family Physicians: 2007 writing group to review new evidence and update the ACC/AHA 2004 guidelines for the management of patients with ST-elevation myocardial infarction, writing on behalf of the 2004 writing committee. Circulation. 2008;117 (2):296-329.

6. Dalal H, Evans PH, Campbell JL. Recent developments in secondary prevention and cardiac rehabilitation after acute myocardial infarction. BMJ. 2004;328(7441):693-7.

7. Smith SC Jr, Allen J, Blair SN, et al. AHA/ACC guidelines for secondary prevention for patients with coronary and other atherosclerotic vascular disease: 2006 update: Endorsed by the National Heart, Lung, and Blood institute. J Am Coll Cardiol. 2006;47(10):2130-9.

8. Flather MD, Yusuf S, Køber L, et al. Long-term ACE-inhibitor therapy in patients with heart failure or left-ventricular dysfunction: A system- atic overview of data from individual patients. The Lancet. 2000;355 (9215):1575-81.

9. Freemantle N, Cleland J, Young P, Mason J, Harrison J. Beta blockade after myocardial infarction: Systematic review and meta regression analysis. BMJ. 1999;318(7200):1730-7.

10. LaRosa JC, He J, Vupputuri S. Effects of statins on risk of coronary disease: A meta-analysis of randomized controlled trials. JAMA. 1999;282:2340-6.

11. van der Elst ME, Bouvy ML, de Blaey CJ, de Boer A. Effect of drug combinations on admission for recurrent myocardial infarction. Heart. 2007;93(10): 1226-30.

12. Austin PC, Tu JV, Ko DT, Alter DA. Use of evidence-based therapies after discharge among elderly patients with acute myocardial infarction. CMAJ. 2008;179(9):895-900.

13. Daugherty SL, Ho PM, Spertus JA, et al. Association of early follow-up after acute myocardial infarction with higher rates of medication use. Arch Intern Med. 2008;168(5):485-91.

14. McGrail KM. Equity in health, health care services use and health care financing in British Columbia, 1992 and 2002 [dissertation]. University of British Columbia; 2006.

15. Wagstaff A, van Doorslaer E, van der Burg $\mathbf{H}$, et al. Equity in the finance of health care: Some further international comparisons. J Health Econ. 1999;18(3):263-92.

16. Morgan S, Coombes M. Income-based drug coverage in British Columbia: Towards an understanding of the policy. Healthcare Policy. 2006;2(2):92-108.

17. Hanley GE, Morgan S, Hurley J, van Doorslaer E. Distributional consequences of the transition from age-based to income-based prescription drug coverage in British Columbia, Canada. Health Econ. 2008;17(12): 1379-92.

18. Population Data BC. 2010 Population Data BC website. Available at: http://www.popdata.bc.ca/. Accessed June 22, 2011.

19. Tran CTT, Laupacis A, Mamdani MM, Tu JV. Effect of age on the use of evidence-based therapies for acute myocardial infarction. Am Heart J. 2004; 148(5):834-41.

20. PharmaNet. Available at: http://www.health.gov.bc.ca/pharmacare/ pharmanet/netindex.html. Accessed June 22, 2011.

21. ATC structure and principles. Available at: http://www.whocc.no/atc/ structure_and_principles/. Accessed June 22, 2011.

22. Williams JI, Young W. Inventory of studies on the accuracy of Canadian health administrative databases. 1996.

23. Weiner JP, Starfield BH, Steinwachs DM, Mumford LM. Development and application of a population-oriented measure of ambulatory care case-mix. Med Care. 1991;29(5):452-72.

24. Hanley GE, Morgan S, Reid RJ. Explaining prescription drug use and expenditures using the adjusted clinical groups case-mix system in the population of British Columbia, Canada. Med Care. 2010;48 (5):402-8

25. Hanley GE, Morgan S. On the validity of area-based income measures to proxy household income. BMC Health Serv Res. 2008;8:79-85.

26. Goldman DP, Joyce GF, Zheng Y. Prescription drug cost sharing. JAMA. 2007;298(1):61-9.

27. Austvoll-Dahlgren A, Aaserud M, Vist GE, et al. Pharmaceutical policies: Effects of cap and co-payment on rational drug use. Cochrane Database Syst Rev. 2008;1(1):1-127.

28. Harris BL, Stergachis A, Ried LD. The effect of drug co-payments on utilization and cost of pharmaceuticals in a health maintenance organization. Med Care. 1990;28(10):907-17.

29. Hux JE, Fielding DA. The ontario drug benefit program copayment: Its impact on access for ontario seniors and charges to the program. Institute for Evaluative Sciences. 1997.

30. Soumerai SB, Avorn J, Ross-Degnan D, Gortmaker S. Payment restrictions for prescription drugs under Medicaid. N Engl J Med. 1987;317(9):550-6.

31. Soumerai SB, McLaughlin TJ, Ross-Degnan D, Casteris CS, Bollini P. Effects of limiting medicaid drug-reimbursement benefits on the use of psychotropic agents and acute mental health services by patients with schizophrenia. N Engl J Med. 1994;331(10):650-5.

32. Tamblyn R, Laprise R, Hanley JA, et al. Adverse events associated with prescription drug cost-sharing among poor and elderly persons. JAMA. 2001;285(4):421-9.

33. Brian EW, Gibbens SF. California's medical copayment experiment. Med Care. 1974;12(12 suppl):1-303.

34. Rasmussen JN, Gislason GH, Rasmussen S, et al. Use of statins and beta-blockers after acute myocardial infarction according to income and education. J Epidemiol Community Health. 2007;61(12):1091-7. 
35. Ohlsson H, Rosvall M, Hansen O, Chaix B, Merlo J. Socioeconomic position and secondary preventive therapy after an AMI. Pharmacoepidemiol Drug Saf. 2010;19(4):358-66.

36. Chernew M, Gibson TB, Yu-Isenberg $\mathbf{K}$, Sokol MC, Rosen AB, Fendrick AM. Effects of increased patient cost sharing on socioeconomic disparities in health care. J Gen Intern Med. 2008;23 (8): 1131-6.

37. Adams AS, Soumerai SB, Ross-Degnan D. Use of antihypertensive drugs by medicare enrollees: Does type of drug coverage matter?. Health Aff. 2001;20(1):276-86.

38. Federman AD, Adams AS, Ross-Degnan D, Soumerai SB, Ayanian JZ. Supplemental insurance and use of effective cardiovascular drugs among elderly medicare beneficiaries with coronary heart disease. JAMA. 2001;286(14):1732-9.

39. Heisler M, Choi H, Rosen AB, et al. Hospitalizations and deaths among adults with cardiovascular disease who underuse medications because of cost: A longitudinal analysis. Med Care. 2010;48(2):87-94.

40. Gerward S, Tydén P, Hansen O, Engström G, Janzon L, Hedblad B. Survival rate 28 days after hospital admission with first myocardial infarction. inverse relationship with socio-economic circumstances. J Intern Med. 2006;259(2):164-72.

41. Dhalla IA, Smith MA, Choudhry NK, Denbur AE. Costs and benefits of free medications after myocardial infarction. Healthcare Policy. 2009;5 (2):68-86. 